\title{
Entorno residencial y habitabilidad urbana en tiempos de pandemia: el caso de Xalapa [México]
}

10.20396/labore.v15i00.8665852

\author{
Mauricio Hernández-Bonilla \\ $<$ https://orcid.org/0000-0002-2620-4621> \\ Universidad Veracruzana / Xalapa [México]
}

Karla Lorena Lozano-Merino

$<$ https://orcid.org/0000-0001-5620-4668>

Universidad Veracruzana / Xalapa [México]

\section{RESUMEN}

En diversos foros especializados en el área de arquitectura y urbanismo se ha debatido sobre la calidad y las condiciones de habitabilidad tanto de la vivienda como del entorno inmediato ante el llamamiento al confinamiento debido a la pandemia generada por el COVID 19. Para el caso mexicano el "quédate en casa", es una de las principales estrategias para mantenerse a salvo y evitar un posible contagio, pero la pregunta que surge es ¿Hasta qué punto nuestra vivienda y entorno urbano inmediato cuentan con las condiciones para poder permanecer en estos por tiempo prolongado? En este artículo, exponemos los resultados de una investigación realizada a través de una encuesta de opinión a los habitantes de la ciudad de Xalapa, Veracruz. Los resultados son reveladores con relación a la valoración del entorno habitacional y la vivienda en el contexto de la emergencia sanitaria por parte de sus usuarios, puesto que ha quedado en evidencia la existencia de deficiencias relevantes en cuanto a la habitabilidad en las viviendas y su entorno inmediato y en materia de espacio público, seguridad, cohesión social e incluso en la propia convivencia social dentro y fuera de las vivienda

\section{PALABRAS CLAVE}

Aislamiento social. Espacio residencial. Espacio urbano y Pandemia. Ciudad-Covid.

\section{Residential environment and urban habitability in Pandemic times: The case of Xalapa [Mexico]}

\begin{abstract}
A large number of forums specializing in the area of architecture and urban planning have discussed the quality and habitability conditions of both housing and the immediate environment in the face of a call for confinement by the authorities. For the Mexican case \#quédate at home, it is one of the main strategies to stay safe and avoid a possible contagion of SARS-CoV-2 better known as Covid-19 or Coronavirus, but the question that persists is to what extent does our immediate housing and urban environment have the conditions to stay in them for a long time?, in this article, we explain the results of a survey through which this question is explored. The results are revealing in relation to the assessment of the housing environment and housing in the context of the health emergency since it has become clear that there are a considerable number of deficiencies in the habitability of homes and their immediate environment and in terms of public space, security, social cohesion and even in the social coexistence itself inside and outside the dwellings. On the other hand, the similarities of the results obtained in various areas of the metropolitan region studied are noteworthy, which makes clear the widespread non-compliance with the right to the city and habitability in the homes.
\end{abstract}

KEYWORDS

Liveabilty. Social isolation. Housing environment. Urban space and Pandemia. 


\section{Introducción}

La situación actual que viven en las ciudades, derivada de la pandemia mundial conocida como COVID-19 o Coronavirus ha dejado en evidencia las desigualdades que existen en la actualidad tanto en la sociedad como en el campo de la arquitectura y el urbanismo, algunas de estas no solo se limitan a una falta de servicios básicos o a la falta de espacios dentro de las viviendas para desarrollar las actividades domésticas en conjunto con las actividades de estudio o trabajo, sino que también se ha hecho evidente la falta de diversos componentes a nivel barrial que satisfagan en el entorno inmediato necesidades como las de abastecimiento, recreación o salud.

Esta situación ha provocado una alarma a nivel mundial, pues tal panorama ha demostrado como, en distintas latitudes; las ciudades, sus espacios y su gente, no están preparadas para llevar a cabo un distanciamiento y aislamiento social a la vez que se pone en evidencia como el espacio y la sociedad tampoco están preparados para regresar a una "nueva normalidad" en donde la vida en el espacio urbano público debe continuar considerando ahora, una nueva realidad que nos lleva a pensar en "la ciudad post-covid".

En México esta situación no ha sido diferente, ya que con la llegada de este fenómeno se ha descubierto que las ciudades son portadoras de un importante déficit en su diseño urbano y la calidad en la habitabilidad de las viviendas y los barrios, situación que se ha hecho aún más evidente con el obligado confinamiento social en los hogares, agravado por la inseguridad de los barrios y el aumento en la violencia familiar y de género que se ha observado desde que las acciones en contra de la pandemia fueron tomadas (Fernández Nieto, 2020).

Por todo lo anterior, se ha levantado todo un debate sobre como el ambiente construido deberá ser diseñado y reacondicionado para crear un entorno habitable más correspondiente a estos tiempos pandémicos. Sin embargo, este proceso de transformación al que podrían someterse las ciudades no podrá desarrollarse con la simple evidencia visual de lo ocurrido durante la pandemia sino que requiere de análisis más detallados de las diversas problemáticas y/o necesidades, y vivencias de las poblaciones urbanas que coadyuven a fundamentar nuevas propuestas y modelos de diseño y/o planificación.

Es por esta situación que el Observatorio Urbano Universitario (OUU) de la Facultad de Arquitectura de la Universidad Veracruzana, región Xalapa ha desarrollado un proyecto de investigación cuya finalidad es conocer la opinión de la ciudadanía sobre la actual situación, así como las problemáticas que enfrenta con relación a su vivienda y entorno inmediato durante la pandemia y el confinamiento provocado por la misma. Este proyecto se ha llevado a cabo con la información obtenida a través de una encuesta a nivel virtual, la cual ha tomado como referente otros trabajos similares (ej. UNAM, ITSM) los cuales han analizado diversos temas que tienen que ver con el entorno habitacional y barrial. El principal objetivo de la presente investigación desarrollada por el OUU es coadyuvar con una serie de reflexiones propositivas como alternativas o ejes de trabajo que contribuyan a aminorar las deficiencias y/o problemáticas que nos impone la situación actual a la vivienda y el entorno urbano y que puedan aproximarse a una reconfiguración de la ciudad y sus componentes en beneficio de los pobladores ante este escenario de emergencia.

El proyecto parte de hacer una pequeña auto-revisión acerca de las cualidades del lugar que habitamos y su contexto, y se pregunta ¿Nuestra casa es cómoda? ¿Cuenta con las condiciones adecuadas para llevar acabo un confinamiento prolongado? ¿Se pueden desarrollar dentro de la vivienda actividades domésticas, de descaso y ocio y al mismo tiempo de estudio y trabajo todos los ocupantes? ¿Qué tanto nuestro entorno barrial cuenta con los satisfactores necesarios para mantenernos dentro de una baja movilidad y poder satisfacer nuestras necesidades diarias de abastecimiento, así como de convivencia?, con base a estos cuestionamientos, este artículo reflexiona los hallazgos más relevantes con relación a la ciudad y el barrio en el contexto de la capital del Estado de Veracruz.

\subsection{LA VIVIENDA, EL BARRIO Y SU HABITABILIDAD EN LAS CIUDADES MEXICANAS}

El acceso a una vivienda digna, con todos los servicios básicos, y espacios necesarios para llevar una vida sana de descanso y ocio y que nos provea de las condiciones adecuadas para el desarrollo de una vida privada y familiar con dignidad ha sido reconocida como un derecho por muchos gobiernos e instituciones a nivel internacional. El derecho al espacio público es otro, lo que hace que sea reconocido como uno de los componentes esenciales dentro la ciudad y sus barrios, el derecho al espacio público significa contar, más allá del ambiente privado de la vivienda, con espacios adecuados y seguros, para llevar a cabo una vida pública de socialización, convivencia e interrelación ciudadana. Dentro de los barrios y colonias, este deberá 
proveer las condiciones adecuadas para la comunicación, el descanso, el juego infantil, la práctica deportiva, el intercambio entre vecinos, y la convivencia comunitaria. Es a través de los usos y vida social que se realiza en los espacios públicos del entorno habitacional donde un barrio o colonia se configura como lugar de identidad y apropiación (Jacobs 1961, Carr et al. 1992, Borja \& Muxi 2003).

Sin embargo, sabemos que en los barrios y viviendas de las ciudades mexicanas existen carencias significativas. Desde el centro hasta la periferia encontramos un deterioro gradual en las características físicas y condiciones de habitabilidad. Los centros sufren de infraestructuras deterioradas y la vivienda frecuentemente presenta muy bajas condiciones de habitabilidad ubicada en edificios antiguos y en gran deterioro. Por otro lado, la periferia informal, con grandes carencias, en las que por mencionar algunas de sus características de origen, no cuentan con infraestructura básica, la vivienda carece de materiales y espacios adecuados, el espacio público de la calle tampoco cuenta con senderos adecuados, banquetas y pavimentos. Cabe mencionar que además existen baldíos y espacios abiertos que aunque podrían funcionar como espacios recreativos no cuentan con la habilitación, infraestructura y equipamientos adecuados, para desarrollar estas actividades.

En otro contexto la vivienda formal periférica creada durante el s. XXI en México, se ha caracterizado por desarrollos habitacionales de interés social, medio e incluso con vivienda para los sectores socioeconómicos de nivel alto con la proliferación de fraccionamientos frecuentemente en suelo urbano al margen y/o aislados de las centralidades y nodos urbanos metropolitanos, depredando el espacio rural y al urbanizar sin áreas verdes, mono-funcionales y frecuentemente distantes de comercios, hospitales, y equipamientos básicos de abastecimiento y/o salud. Ya no hablar de transporte público, tampoco se cuenta de vías de comunicación adecuadas, tampoco sistemas de movilidad y transporte sustentables y en general, independientemente del estrato el que vaya dirigido la mala planificación en su conjunto y concordancia con el contexto y considerando los impactos a nivel ciudad han conllevado a una calidad de vida cada vez más deficiente. Desde el punto de vista social, estos entornos urbanos en las últimas dos décadas han sido impactados por la inseguridad y violencia, lo que ha ahondado la fragmentación social, las desigualdades, proliferando un mayor individualismo, con su impacto en el debilitamiento del tejido social y sus lazos comunitarios, finalmente mermando la configuración de identidad social barrial.

Es en este contexto urbano de carencias y con estas condiciones urbanas y habitacionales es donde una gran mayoría de la población mexicana habita y recibe una pandemia que implica confinarse y aislarse socialmente, para estar más seguros y más protegidos de tal amenaza sanitaria. Son estas condiciones en las que resulta pertinente el cuestionamiento de cómo responden ante una situación de largo confinamiento y como en el espacio familiar privado de la vivienda y semi-privado o semi-público del barrio se pueden desarrollar nuestras actividades cotidianas (domésticas y de convivencia familiar) que además ahora se necesitan desarrollar por periodos más prolongados. Además, se suman las actividades laborales y de estudio que en la normalidad se desarrollan en otros espacios como escuelas, oficinas, y otros lugares de estudio y/o trabajo.

\subsection{EL COVID 19: LA CIUDAD Y EL BARRIO}

En muchos países, el COVID 19 ha cambiado la cara de las ciudades y fundamentalmente la discusión de cómo deberíamos gestionar la vida urbana en el contexto de una pandemia (Acuto 2020). Ya en diversas investigaciones se ha hecho evidente, las deficiencias, la minimización y la disminución de la calidad del espacio habitacional en las políticas públicas habitacionales en las últimas décadas (ej. Zicardi \& González 2015). Por otro lado, la pandemia ha ahondado estas deficiencias, pues al permanecer en la vivienda por periodos más prolongados y tratar de desarrollar además de las actividades familiares y domésticas, ahora en un periodo de aislamiento y emergencia sanitaria también se intentan realizar actividades de trabajo, estudio, deporte y/o ejercicio. Aquí es donde la alta densidad, los espacios mínimos, el hacinamiento, la falta de una terraza o un balcón para el respiro, la falta de un espacio para el estudio o el teletrabajo, son identificados como problemáticas con relación al ámbito habitacional. La emergencia sanitaria ha evidenciado que estas condiciones, no son particulares de la vivienda de países pobres o subdesarrollados, también se ha hecho evidente que en países de mayores recursos se sufren deficiencias similares (Century 2 España, 2020).

En este contexto, se han iniciado diversas investigaciones con relación a las ciudades y las condiciones en que se vive el llamamiento a aislarse y quedarse en casa ante las condiciones de incertidumbre sanitaria ocasionadas por la Covid 19. Por ejemplo, el Instituto de investigaciones en Ciencias Sociales de la UNAM 
ha congregado a diversos investigadores para conocer las condiciones de habitabilidad de las viviendas y el entorno urbano ante el aislamiento social en el contexto del COVID-19 en diversas ciudades mexicanas (Zicardi, 2020:2), aquí se argumenta que:

"La experiencia de confinamiento en el interior de las viviendas expresa y amplifica las desigualdades estructurales que existen en estas ciudades y las limitaciones que se observan para hacer efectivo el derecho a la salud, a la educación, a la vivienda, al espacio público y al trabajo los cuales como ha quedado descubierto con la pandemia están interrelacionados" (Zicardi, 2020).

En este mismo sentido, el centro CEMEX-TEC de Monterrey ha emprendido estudios para determinar el nivel de vulnerabilidad de las viviendas a través de un Índice de Vulnerabilidad en Infraestructura de la Vivienda ante el Covid-19 (IVIV-COVID). De acuerdo con sus resultados: en México, el número estimado de hogares habitados es de 34.1 millones, de los cuales, 1.7 se encuentra en rezago por hacinamiento, es decir, aproximadamente el 5\% de todas las viviendas; y 7.5 millones $(22 \%)$ tienen rezago por la mala calidad en los materiales de construcción. El 11.1\% de la población mexicana enfrenta carencias de calidad en los espacios para habitar, y el 19.8\% no tiene acceso a servicios básicos (González D., 2020).

$\mathrm{Al}$ respecto, nos dice el sociólogo Fernando Campos:

\begin{abstract}
"Es el momento de pensar en una ciudad más equitativa con los estándares de vida, es brutal que eso no esté en discusión hoy día y es brutal también que mandemos a la gente a hacer cuarentena en su casa, pero no tengamos idea de en qué condiciones vive. Aquellos que aún no se hayan dado cuenta de la verdadera calidad del espacio en el que viven, lo harán ahora gracias a la cuarentena, y aún más si el virus se convierte en una normalidad de duración incierta" (Espinoza, 2020)
\end{abstract}

Hablando más allá de los límites de la vivienda, es decir del entorno barrial, la ONU-Hábitat ha destacado que la pandemia por Covid-19 ha puesto en evidencia la desigualdad en la distribución del espacio público en muchas ciudades del mundo, especialmente en barrios pobres, donde hay pocos espacios compartidos, como áreas verdes o parques. No obstante, estos espacios son importantes para contribuir a reducir los niveles de estrés, así como para mejorar la salud mental y el bienestar. El organismo señala que el espacio público debe ser parte de la respuesta a la pandemia, tanto para limitar la propagación del virus como para proporcionar alternativas para que las personas continúen su vida en la 'nueva normalidad'. (Hernández, 2020c). Otros comentaristas (Arief, 2020) han argumentado, desde el punto de vista del diseño, que no es que este vaya a resolver la crisis del coronavirus en las ciudades, sino que la pandemia ha demostrado que se pueden cerrar calles al tránsito vehicular para crear espacios más habitables, más seguros, y con aire más limpio, que se puede gestionar las ciudades de una manera diferente y que incluso con estas estrategias se podría combatir el cambio climático.

Así también, Hernández (2020a) de Centro Urbano comenta "Es esencial que los gobiernos adopten medidas para que las personas tengan acceso a viviendas asequibles y a espacios públicos; y que garanticen un crecimiento urbano planificado que mejore las condiciones de vida de los residentes de asentamientos informales". En el mismo tenor, Martí y Velázquez (2020:168) apuntan que la necesidad de intervenir en el espacio privado es urgente, considerando la necesidad de extender los servicios de infraestructura básica a todos los sitios urbanos, propiciando la equidad social y sustentando el ejercicio de un derecho a la vivienda que permita que ésta se constituya en un refugio efectivo en tiempos de calamidad. A nuestro parecer, no solo en asentamientos informales se hacen necesarias estrategias y acciones, sino a lo largo y ancho de las ciudades. Ya lo comentaba la su subsecretaria de Desarrollo Urbano y Vivienda de la SEDATU, La pandemia ha puesto de manifiesto que el territorio debemos intervenirlo de manera integral (Hernández, 2020b).

Sin embargo, para poder llevar a cabo cambios y propuestas para encaminarnos a la reconfiguración de los espacios habitables, las viviendas, los espacios públicos, los barrios y en general las ciudades, es importante hacer estudios desde diversas perspectivas e incluso con una visión transdisciplinar que nos lleven a conocer las carencias que experimentan las personas en sus viviendas y sus barrios en estos momentos cruciales de aislamiento y distanciamiento. A continuación, presentamos la metodología de la investigación realizada en nuestro estudio.

\title{
2. Aproximación metodológica
}

El estudio emerge del Observatorio Urbano Universitario de la Universidad Veracruzana, con sede en la Facultad de Arquitectura de Xalapa. Este Observatorio, es un ente que aglutina a diversos investigadores en 
el área de la arquitectura y urbanismo, teniendo como uno de sus objetivos principales monitorear de manera constante diversos fenómenos urbanos a través de la medición de indicadores relacionados con la vivienda, el espacio público, los equipamientos, el patrimonio, los usos de suelo y la equidad de género en la ciudad de Xalapa. Es en este contexto de investigación donde se plantea el estudio del entorno residencial y urbano para la ciudad de Xalapa bajo las condiciones que ha implantado el COVID19 y el aislamiento social.

Para el estudio se partió principalmente de una encuesta en línea para ser contestada por cualquier persona a través de un dispositivo digital (computadora o teléfono). De este modo, se diseñó un cuestionario conformado por 35 preguntas de opción múltiple del cual se obtuvieron un total de 168 ejemplares respondidos principalmente por personas que habitan en el Área Metropolitana de Xalapa. Las preguntas puntuales dentro del cuestionario abarcaron diversos temas y/o categorías relacionadas a la habitabilidad de la vivienda, los servicios básicos y de comunicación con los que ésta cuenta, el entorno habitacional y urbano, el espacio público inmediato, el uso de los espacios y el entorno social, así como la percepción de seguridad (Ver Tabla 1).

Tabla 1. Temáticas y categorías de las preguntas desarrolladas en la encuesta virtual. Elaboró: Karla Lozano (2020).

\begin{tabular}{|c|c|}
\hline Temáticas & Categorías \\
\hline \multirow[t]{6}{*}{ Habitabilidad } & Tipología de vivienda \\
\hline & Propiedad de la vivienda \\
\hline & Calidad espacial de la vivienda \\
\hline & Actividades realizadas dentro de la vivienda en pandemia \\
\hline & Seguridad \\
\hline & Violencia \\
\hline \multirow[t]{2}{*}{ Servicios } & Servicios básicos (agua, luz y drenaje) \\
\hline & Servicios de internet y telefonía \\
\hline Tecnología digital & Utilización de recursos digitales \\
\hline \multirow[t]{4}{*}{ Entorno urbano } & Espacios de recreación en el barrio o colonia \\
\hline & Espacios abiertos en viviendas \\
\hline & Calidad de las calles aledañas a la vivienda \\
\hline & Equipamiento comercial y comunitario \\
\hline \multirow[t]{4}{*}{ Entorno social } & Ocupación de los habitantes \\
\hline & Cantidad de personas en la misma vivienda \\
\hline & Roles de actividades por género en los hogares \\
\hline & Convivencia y apoyo vecinal \\
\hline Movilidad & Traslados de la población (Ruptura del estado de cuarentena) \\
\hline \multirow[t]{2}{*}{ Información sobre COVID } & Equipamiento (especializado en el tratamiento de COVID) \\
\hline & Procedimiento en caso de contagio \\
\hline \multirow[t]{3}{*}{ Percepción social } & Seguridad \\
\hline & Violencia \\
\hline & Acción gubernamental ante la pandemia (nivel federal y municipal) \\
\hline
\end{tabular}

Una buena fuente de información fueron los estudiantes de la Universidad Veracruzana, así como sus familiares y amigos, de esta manera se difundió la encuesta en los diversos espacios digitales y redes sociales tanto de la Facultad de arquitectura como del OUU de la Universidad Veracruzana. La encuesta fue publicada entre mayo y agosto del 2020, estando disponible por un plazo de 2 meses.

Con base en los resultados de la encuesta, se realizó un análisis cartográfico, utilizando software SIG (Qgis) para relacionar las respuestas de los entrevistados con el territorio de la ciudad y así reflexionar sobre las 
percepciones de las personas y lo que esto manifestado en el territorio nos podría aportar para entender la dinámica territorial de la ciudad con relación a los temas abordados, la situación de confinamiento y la pandemia. A continuación, discutiremos los resultados más relevantes.

El cuestionario fue contestado por 105 mujeres y 63 hombres, de los cuales el rango de edad de los participantes osciló 18 y 60 años, el mayor grupo de participación lo tuvimos con personas de entre 18 y 30 años. Así, que nuestros informantes fueron en su mayoría estudiantes y trabajadores asalariados. La mayoría de sus hogares están ocupados en un rango 2 a 4 personas, con integrantes de diversas edades desde adolescentes hasta adultos mayores. Algunas particularidades que se deben hacer notar es la disminuida participación de niños (menores de 15 años) así como la recepción de respuestas en la mayoría de los casos provenientes de la población que habita en el Centro de la ciudad de Xalapa ${ }^{1}$ (ver Figura 1). En los siguientes párrafos discutiremos principales resultados del estudio agrupados en las principales temáticas abordadas.

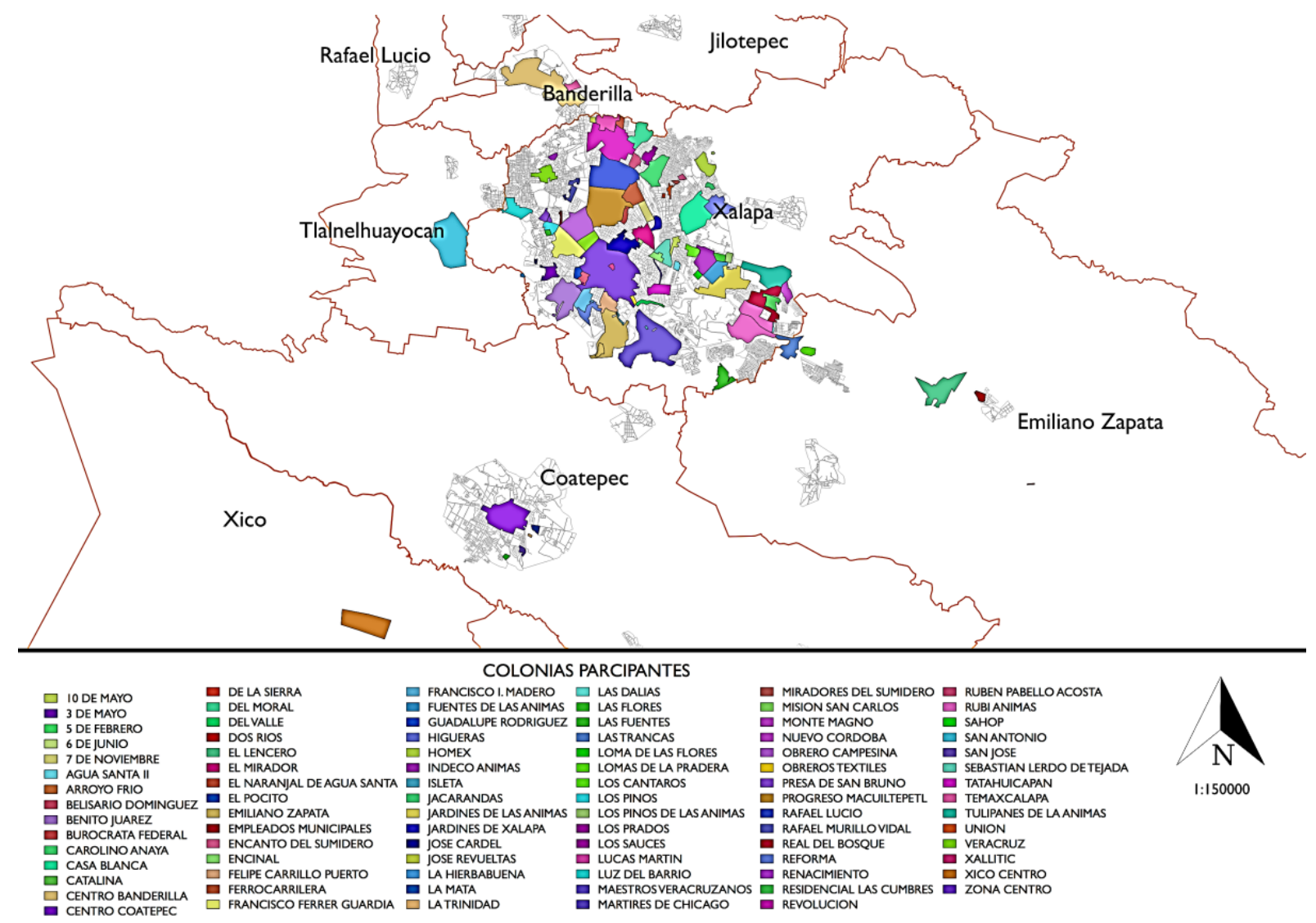

Figura 1. Localización de las colonias participantes. Fuente: Encuesta virtual Entorno Residencial y Habitabilidad durante el confinamiento social por COVID-19. Elaboración: Karla Lozano Colaboración: Gabriela Domínguez (2020).

\section{Resultados}

\subsection{HABITABILIDAD DE LA VIVIENDA}

En lo que corresponde al tema de Habitabilidad donde a los encuestados se les solicitó información sobre la tipología su vivienda, el régimen de propiedad de la vivienda, la calidad espacial de su vivienda así como de las actividades realizadas dentro de la vivienda en pandemia.

La mayoría de nuestros encuestados viven en vivienda unifamiliar y propia (Figura 2); las actividades que estos realizan en su vivienda dentro de la pandemia son diversas, sobresaliendo las actividades del teletrabajo (trabajo en línea), estudiar en línea, realizar tareas domésticas, navegar en la red, así como ver televisión en las plataformas streaming.

\footnotetext{
${ }^{1}$ Cabe mencionar que aunque se recibieron respuestas de diversos lugares de la Zona Metropolitana de Xalapa, para considerar una mayor aproximación a resultados más concretos, solo se tomaron en cuenta los resultados obtenidos para la ciudad de Xalapa.
} 


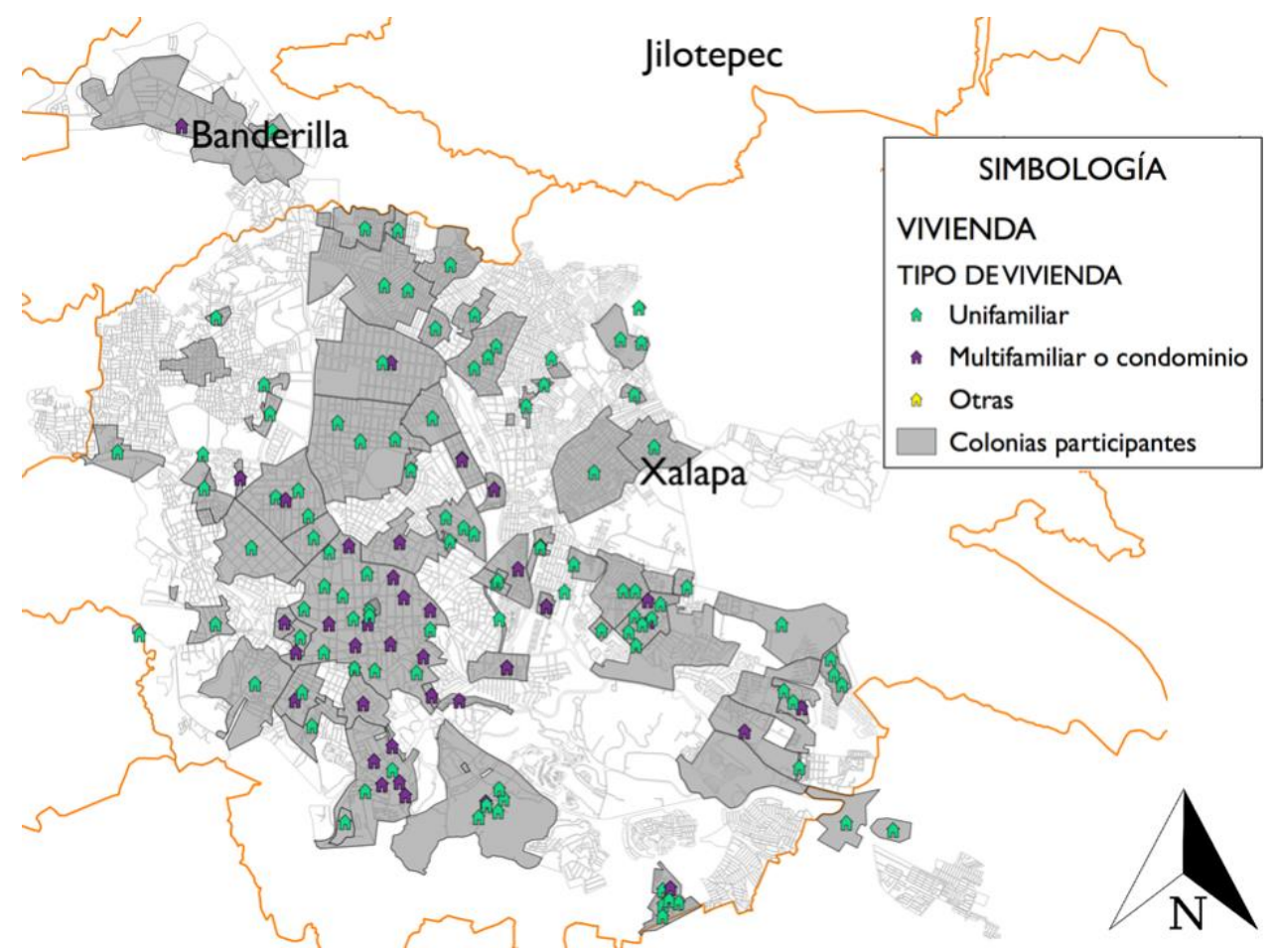

Figura 2. Tipologías de vivienda de los encuestados. Encuesta virtual Entorno Residencial y Habitabilidad durante el confinamiento social por COVID-19. Elaboración: Karla Lozano (2020).

Estos resultados arrojaron también una marcada diferencia en cuanto a la calidad de la habitabilidad entre la periferia y el centro de la ciudad pues tal como se muestra en la Figura 3, podemos advertir una mayor cantidad de espacios para el desarrollo de actividades propias del confinamiento en las viviendas localizadas en el centro de la ciudad mientras que en la periferia se presentan con mayor frecuencia, los casos en los que la vivienda cuenta con solo una habitación para el desarrollo de las actividades.

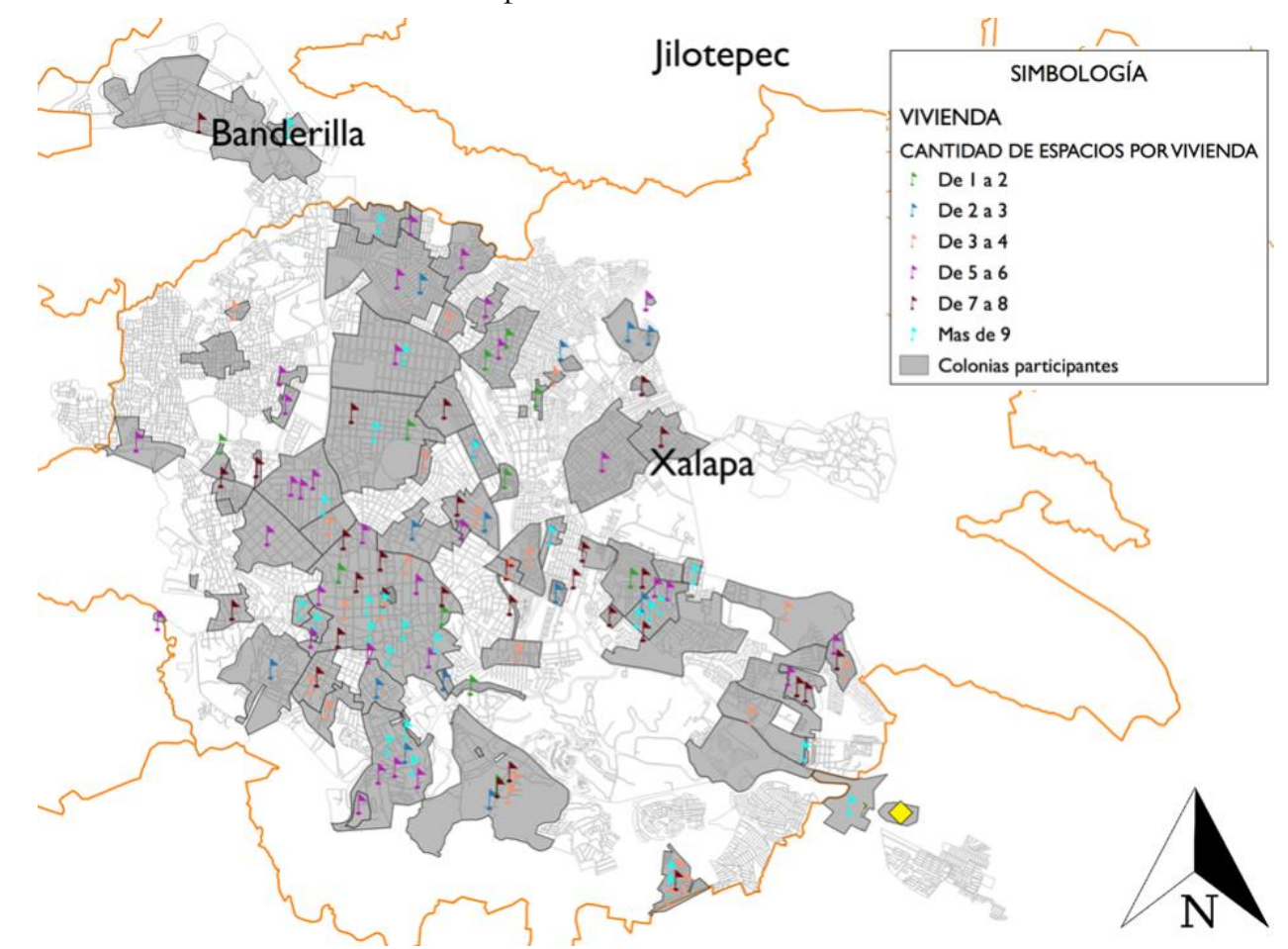

Figura 3. Cantidad de habitaciones por vivienda para la realización de actividades. Fuente: Encuesta virtual Entorno Residencial y Habitabilidad durante el confinamiento social por COVID-19. Elaboración: Karla Lozano (2020).

Por otro, se hace evidente que ante la falta de un espacio adecuado para el desarrollo de actividades académicas y estudio, surge la necesidad de utilizar otros espacios tales como la sala, el comedor, la recamara, la 
cocina u otros. Esto se manifiesta en la importancia del comedor en el desarrollo de estas actividades (ver Figura 4). Sin embargo, es importante resaltar como en las viviendas de la periferia el espacio de la cocina es utilizado para tales actividades, lo que podría ser resultado de la falta de más espacios dentro de la vivienda.

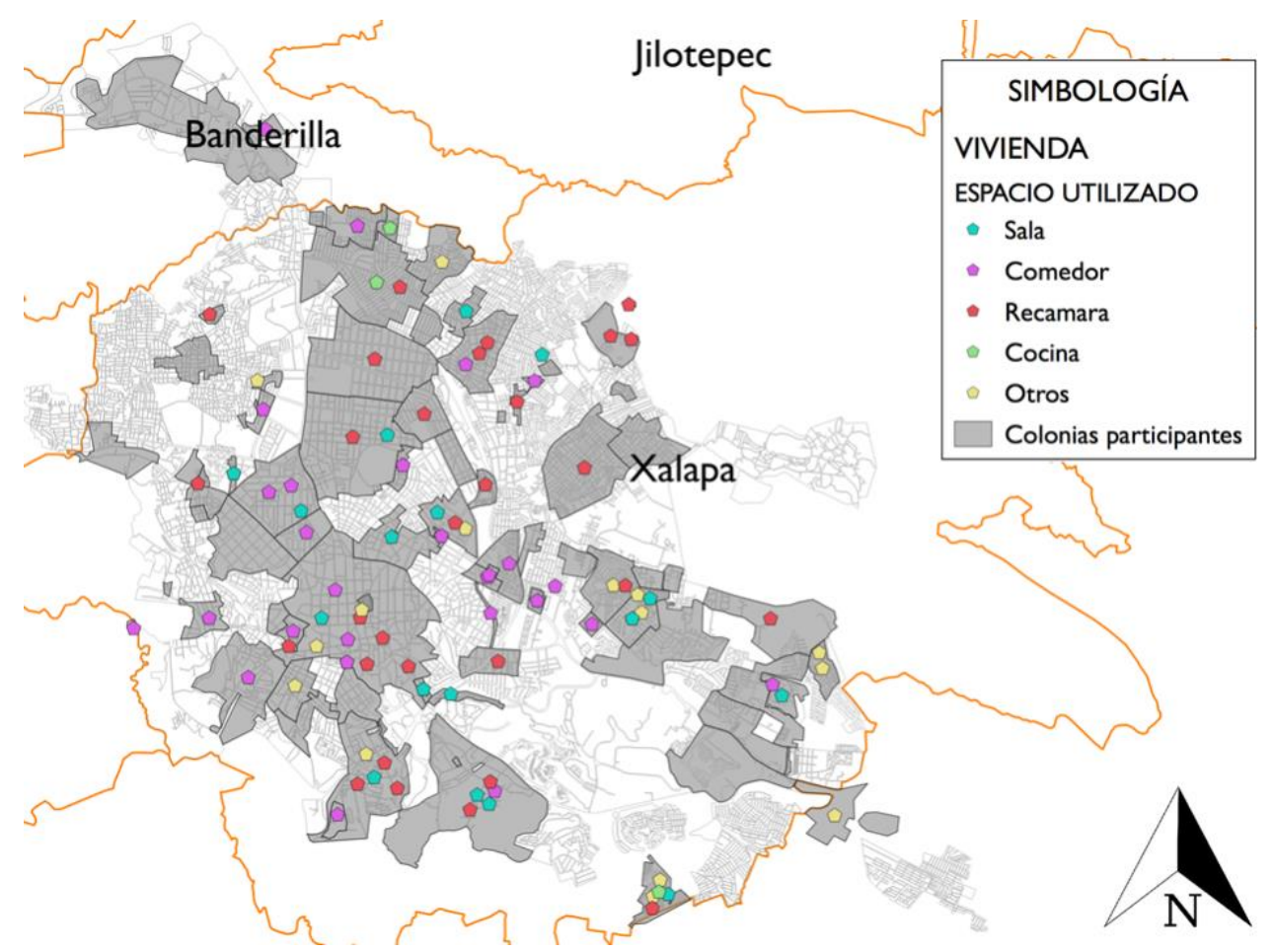

Figura 4. Espacios comúnmente utilizados para el desarrollo de actividades laborales o académicas. Fuente: Encuesta virtual Entorno Residencial y Habitabilidad durante el confinamiento social por COVID-19. Elaboración: Karla Lozano. (2020).

En relación, a la presencia de espacios abiertos que funcionen con un objetivo recreativo o de descanso dentro de los hogares se expresó la importancia de su existencia en las viviendas Xalapeñas, representados en su mayoría por balcones, terrazas y jardines. Sin embargo, estos espacios continúan siendo insuficientes en las viviendas de la periferia (ver Figura 5).

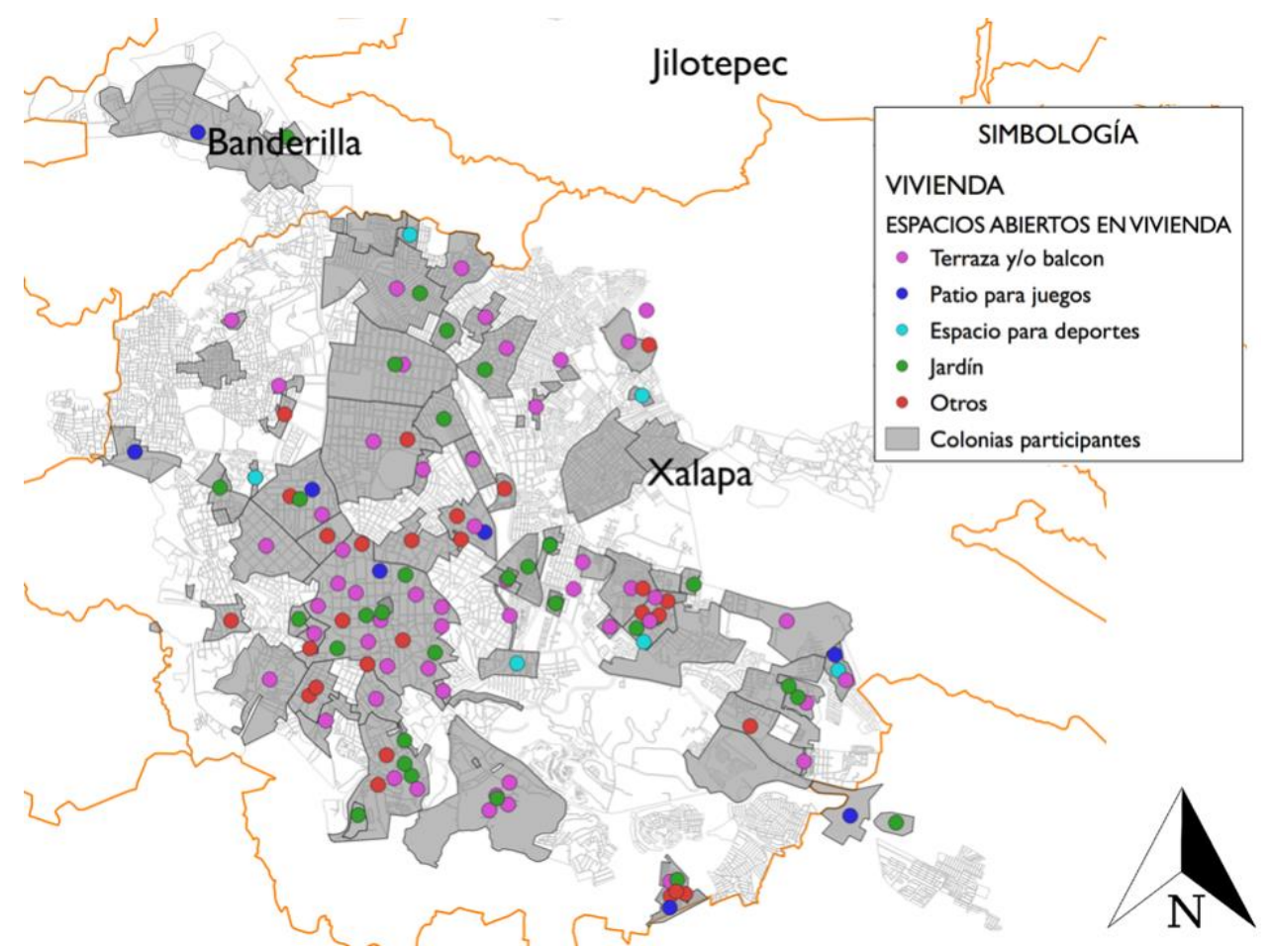

Figura 5. Presencia de espacios abiertos en la vivienda. Encuesta virtual Entorno Residencial y Habitabilidad durante el confinamiento social por COVID-19. Elaboración: Karla Lozano (2020). 
En el caso de la tipología de las viviendas se puede observar como la existencia de una mayor cantidad de viviendas multifamiliares o en condominio en el centro de la ciudad demuestra una mayor cantidad de personas confinadas en la zona céntrica en un solo inmueble o conjunto de viviendas, lo que posiblemente podría influir en la manera de cómo se propaga el virus. Por el contrario, en la zona periférica, la presencia de un mayor porcentaje de viviendas unifamiliares es una evidencia de que a pesar de la cantidad de personas que habitan la zona podría existir un confinamiento más seguro. Aunque, por supuesto debemos reconocer que esto no es determinante para el contagio. Esto depende en la realidad de muchos otros factores. Sin embargo, resultados de recientes investigaciones ${ }^{2}$ apuntan que la densidad es solo uno de los muchos factores que influyen en la vulnerabilidad ante el COVID 19 (Zhong \& Teirlinck, 2020).

\subsection{SERVICIOS Y TECNOLOGÍA DigITAL}

En cuanto a esta categoría se pudo observar como la infraestructura en las viviendas es la oportuna puesto que, según los encuestados, la mayoría cuenta con los servicios básicos en sus hogares tales como agua potable y drenaje esenciales para una correcta limpieza en los hogares y la energía eléctrica e internet, necesarios para el constante trabajo (laboral o escolar) a distancia. Así mismo, se obtuvo información acerca del cambio en infraestructura que no fue necesaria a consecuencia del confinamiento y la continuidad de las actividades diarias y al respecto, se advirtió poca diferencia entre la infraestructura de comunicaciones existente y las nuevas adecuaciones. Lo anterior debido a que la mayoría de las viviendas ya contaban con servicios de internet antes del confinamiento (ver Figura 6).

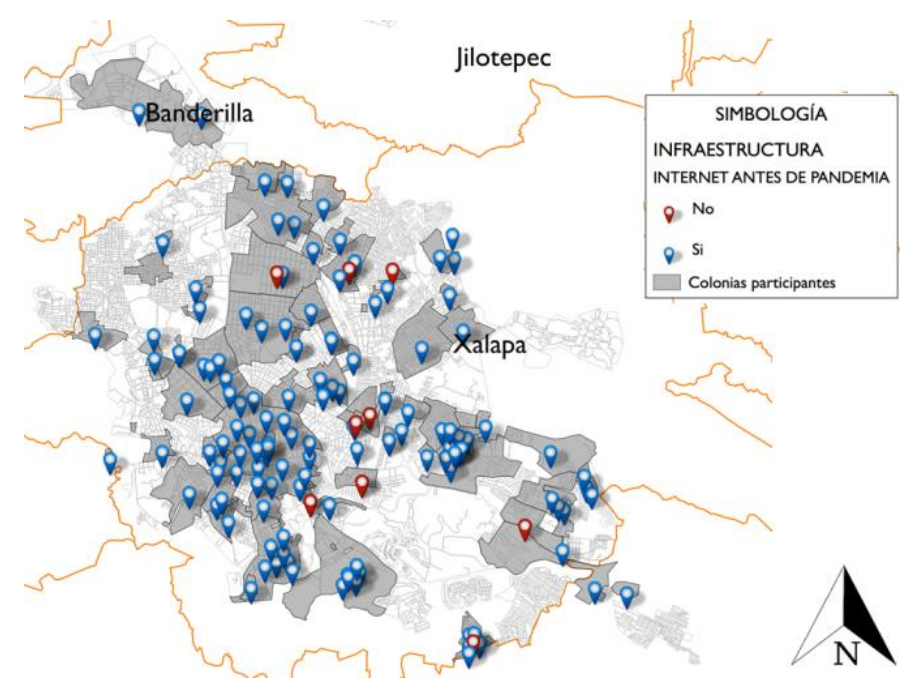

Figura 6. Presencia de internet en las viviendas. Encuesta virtual Entorno Residencial y Habitabilidad durante el confinamiento social por COVID-19. Elaboración: Karla Lozano (2020).

Además, se realizaron algunas preguntas enfocadas a la necesidad y utilización de dispositivos electrónicos por personas que habitan en la misma vivienda, y en muchos de los casos solo se cuenta con un ejemplar para la utilización de toda la familia (Equipo de cómputo, internet, impresora, etc.). El resultado es de interés, pues en la mayoría de los casos el uso de aparatos digitales de manera sincrónica es desarrollado hasta por 2 o tres personas (ver Figura 7). Este es un asunto de importancia pues las limitantes $y$ demandas por los dispositivos electrónicos por los habitantes, podría resultar una situación conflictiva $\mathrm{y} / \mathrm{o}$ limitante para poder continuar con las actividades educativas y laborales a distancia.

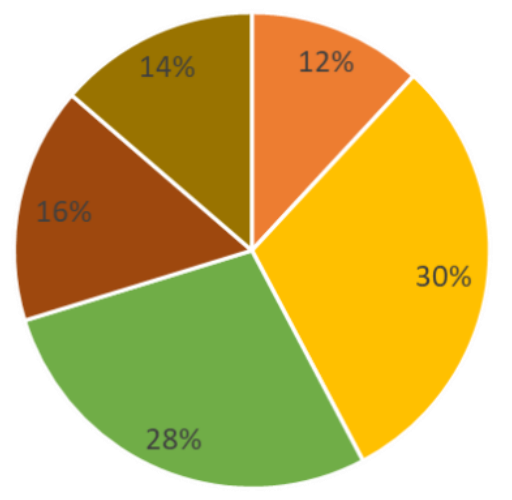

- 1 persona

- 2 personas

- 3 personas

- 4 personas

- Más de 4 personas

\footnotetext{
${ }^{2}$ La evidencia de contagios en ciudades densamente pobladas demuestra que esto no es factor determinante, de hecho en ciudades densamente pobladas y donde la mayoría de sus habitantes habitan en grandes edificios con cientos de departamentos han registrado mucho menor cantidad de contagios en comparación con otras similares (ver Zhong \& Teirlinck, 2020).
} 


\subsection{ENTORNO SOCIAL}

En relación a la distribución de las tareas dentro del hogar de acuerdo con su participación tanto de hombres como mujeres, alrededor de la mitad de los encuestados nos comentaron que las tareas en casa se distribuyen entre toda la familia (Figura 8). Sin embargo, alrededor de un $41 \%$ comentaron que las mujeres son las que en su mayoría llevan a cabo las tareas domésticas y solo un $6 \%$ de los encuestados, comentaron que son los hombres los que se encargan de realizar las tareas propias del hogar. Esto nos da muestra, que la mujer sigue ocupando un rol importante en la realización de las tareas domésticas. Aunque, de acuerdo con las respuestas, esto va cambiando pues cada vez más existe una igualdad al realizar dichas tareas del hogar y distribuirse de manera más equitativa entre los miembros de la familia, sin importar su género.

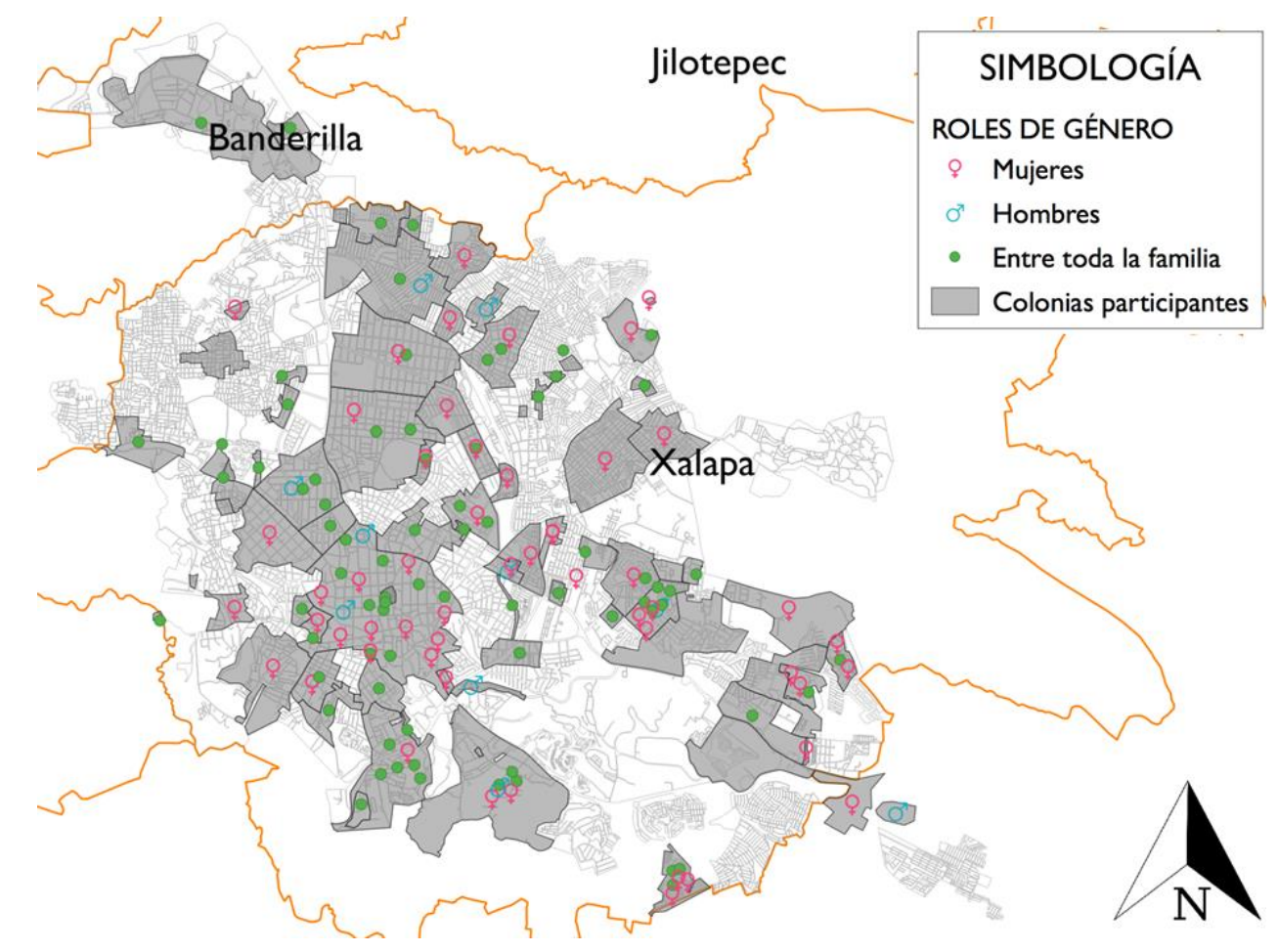

Figura 8. Roles de género detectados dentro de las viviendas para el desarrollo de las actividades propias del hogar ante el cuestionamiento sobre ¿quien desarrolla las tareas del hogar? Encuesta virtual Entorno Residencial y Habitabilidad durante el confinamiento social por COVID-19. Elaboración: Karla Lozano (2020).

\subsection{ENTORNO URBANO}

En relación con el entorno urbano y la presencia de servicios comerciales y equipamiento dentro de los barrios, es un mínimo porcentaje el que contestó no contar con establecimientos comerciales para abastecerse de alimentos cerca de su hogar durante el periodo de resguardo y distanciamiento durante esta pandemia. Por lo menos, dentro de los barrios existe una tienda de conveniencia cerca de los hogares; por otro lado, el mercado público y el supermercado son los que se encontrarían más distantes para algunas zonas de la periferia. Aunque, se puede observar una marcada presencia de pequeños comercios de productos básicos cercanos a la vivienda en estas zonas (tiendas de barrio y de cadena).

De igual forma, los resultados en cuanto a la presencia de espacios públicos para la recreación cercanos a la vivienda y su nivel de utilización expresados en la Figura 9, solo una tercera parte dijo contar con un área verde cerca de su vivienda, otra tercera parte dijo no contar con este tipo de espacios dentro de su barrio y finalmente la otra tercera parte dijo contar con alguna plazoleta, parque de barrio o zona deportiva.

Esto da cuanta sobre lo importante que es, la existencia de los espacios públicos para la recreación y el descanso dentro de los barrios y colonias; más aún, en estos tiempos de pandemia, donde se ha restringido y/o prohibido el acceso a los espacios abiertos públicos recreativos en la ciudad de Xalapa por parte de las autoridades municipales. En este sentido, la calle también juega un rol importante dentro de los barrios como espacio público (ver Figura 9). Más allá de ser un espacio de circulación, considerarlo como un espacio recreativo dentro del entorno barrial es de suma importancia, pues un poco más de la mitad $(53 \%)$ de 
nuestros encuestados respondieron que utilizaban la calle en donde se localizan como espacio recreativo y el resto $(47 \%)$ que no la utilizaban. Los que no utilizan entre otras razones es debido principalmente al excesivo tránsito vehicular (Figura 11), lo que hace que sus calles sean inseguras y poco adecuadas para el juego, paseo, descanso o relajación.

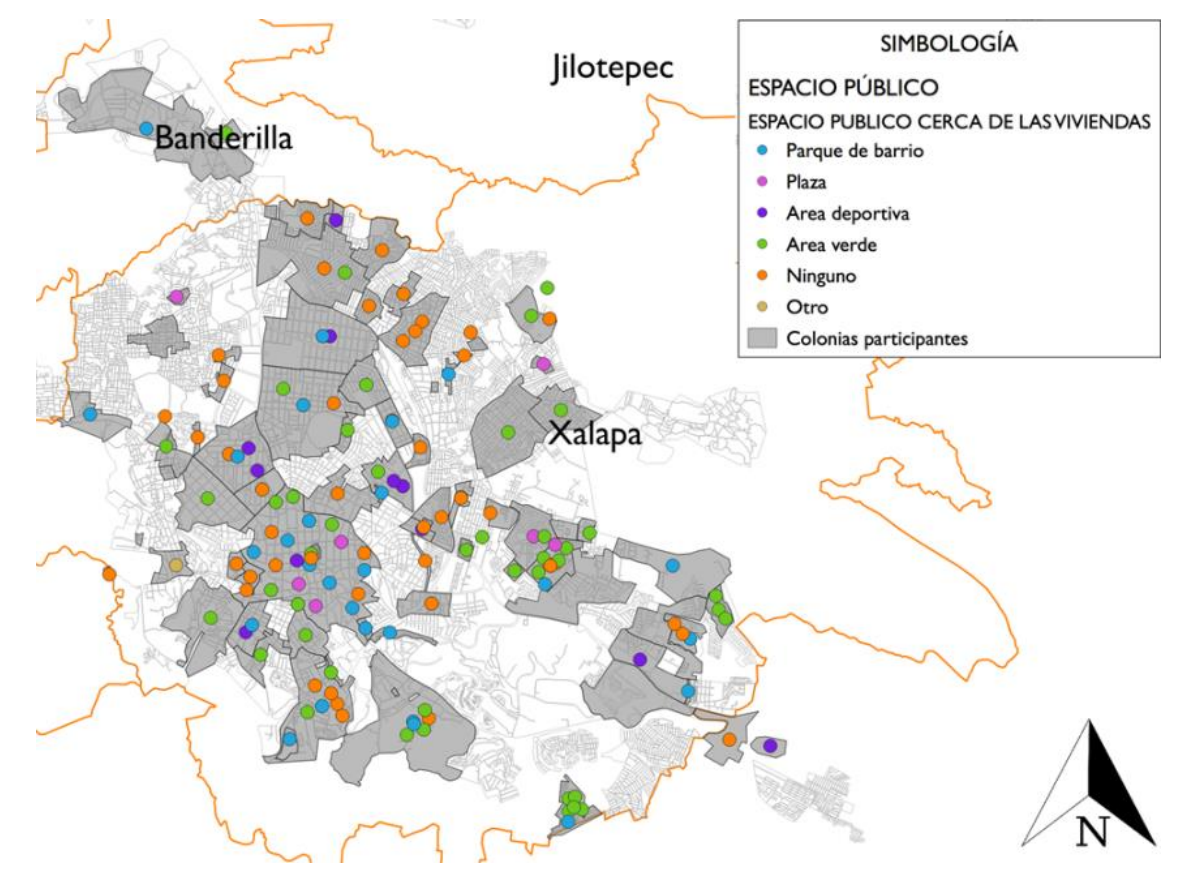

Figura 9. Presencia de espacios abiertos públicos cerca de la vivienda. Encuesta virtual Entorno Residencial y Habitabilidad durante el confinamiento social por COVID-19. Elaboración: Karla Lozano (2020).

Por otro lado, es evidente la diferencia en la percepción social de la población entre la que reside en el centro y la que se localiza en la periferia, pues los resultados de la Figura 10 nos permiten observar como la tendencia a considerar las vialidades como un espacio recreativo es mucho más fuerte en las periferias de la ciudad, lo cual en la mayoría de los casos podría deberse a una menor concentración vehicular en estas zonas de la ciudad.

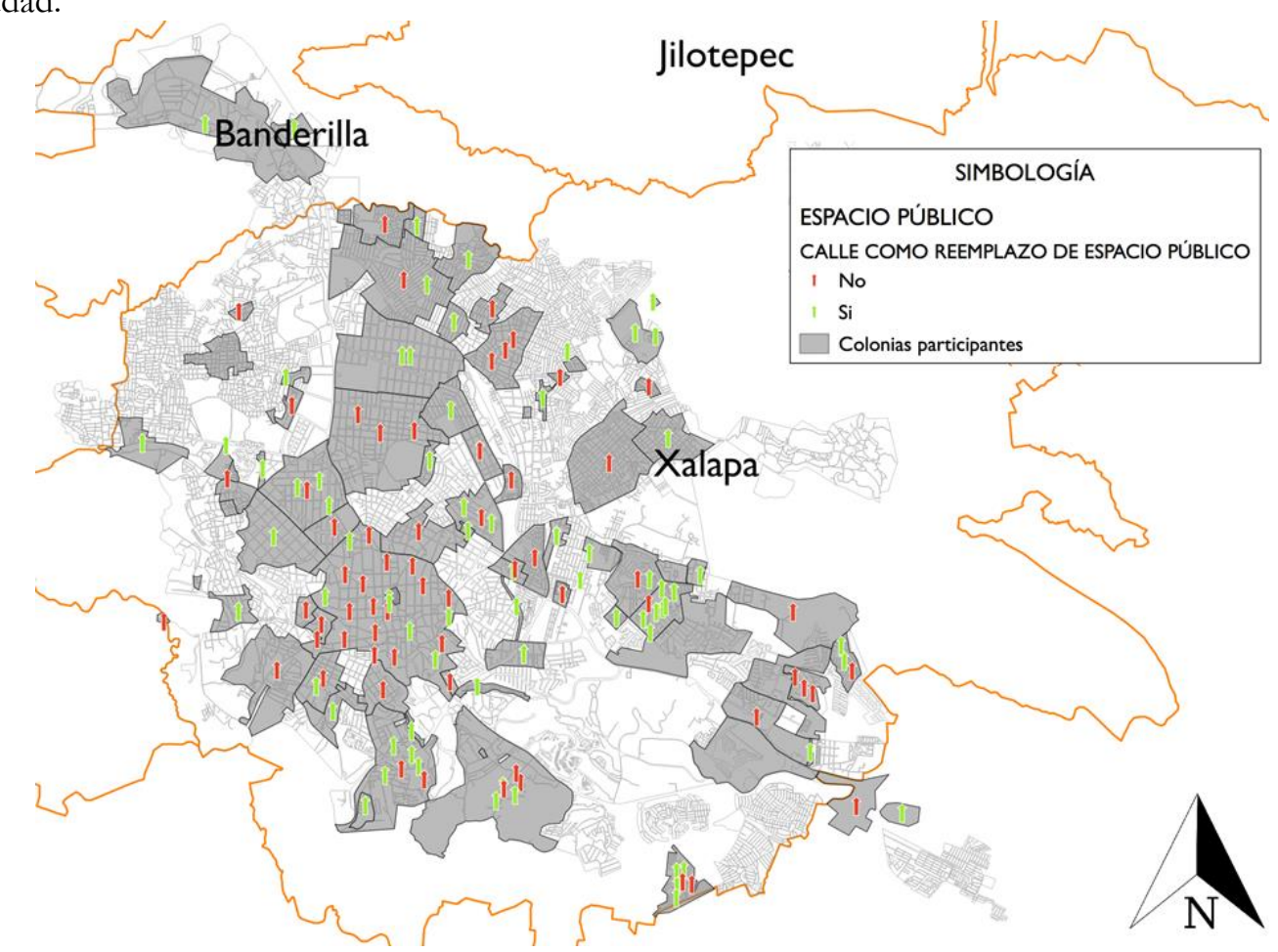

Figura 10. Utilización de las calles como espacio recreativo. Encuesta virtual Entorno Residencial y Habitabilidad durante el confinamiento social por COVID-19. Elaboración: Karla Lozano (2020). 


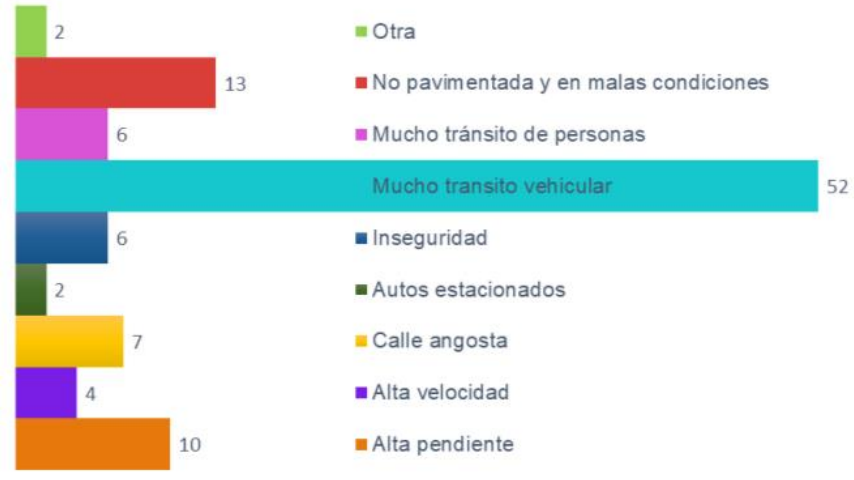

Figura 11. Motivos por los que la ciudadanía considera que la calle no es segura para utilizarse como espacio recreativo alterno. Encuesta virtual Entorno Residencial y Habitabilidad durante el confinamiento social por COVID-19. Elaboración: Karla Lozano (2020).

Otro tema importante con relación a la pandemia y el entorno barrial es sobre la existencia de equipamientos de salud como clínicas y hospitales, cercanos a la vivienda, al respecto la mayoría no cuenta con estos servicios dentro de su colonia y la mayoría de las personas los percibe ubicados alejados fuera de sus barrios y a largas distancias. (ver Figura 12) A pesar de notarse cierta distribución uniforme en la existencia del servicio hospitalario en la ciudad, la cercanía de este servicio para las zonas periféricas se considera deficiente.

En relación con la movilidad se analizaron las causas por las cuales la ciudadanía se ve en la necesidad de interrumpir el confinamiento, es importante notar como la búsqueda de alimentos es una de las principales causas y en menor medida por otras actividades como las laborales (Figura 13).

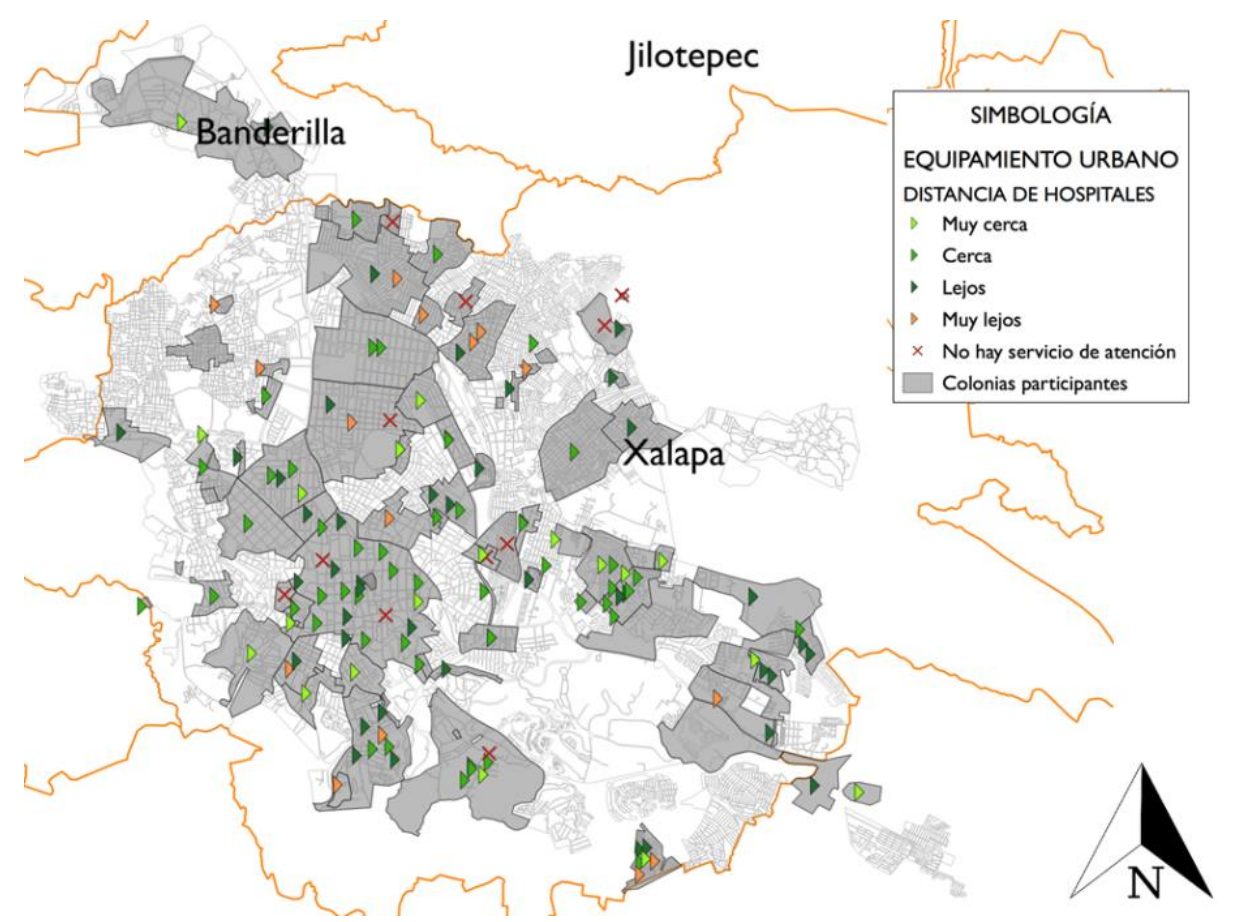

Figura 12. Servicios hospitalarios cercanos a las viviendas. Encuesta virtual Entorno Residencial y Habitabilidad durante el confinamiento social por COVID-19. Elaboración: Karla Lozano (2020).

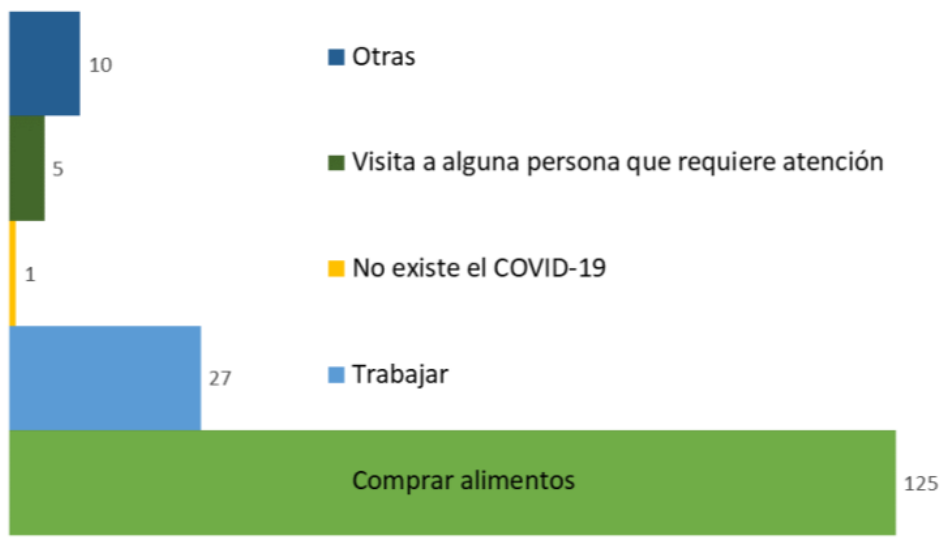

Figura 13. Motivos por los que la ciudadanía se ha visto en la necesidad de trasladarse fuera de casa o romper el aislamiento. Encuesta virtual Entorno Residencial y Habitabilidad durante el confinamiento social por COVID-19. Elaboración: Karla Lozano (2020). 


\subsection{ENTORNO SOCIAL Y SEGURIDAD}

El tema de la seguridad es otro asunto importante con relación a las colonias y barrios de las ciudades, y los robos a casa habitación o la violencia en las calles, como sabemos es un problema en muchas ciudades en México. Xalapa, no ha alcanzado los niveles de inseguridad o violencia como los de otras ciudades por lo que las personas aun gozan de sentirse seguros en sus viviendas y en sus barrios tal como se muestra en la Figura 14.

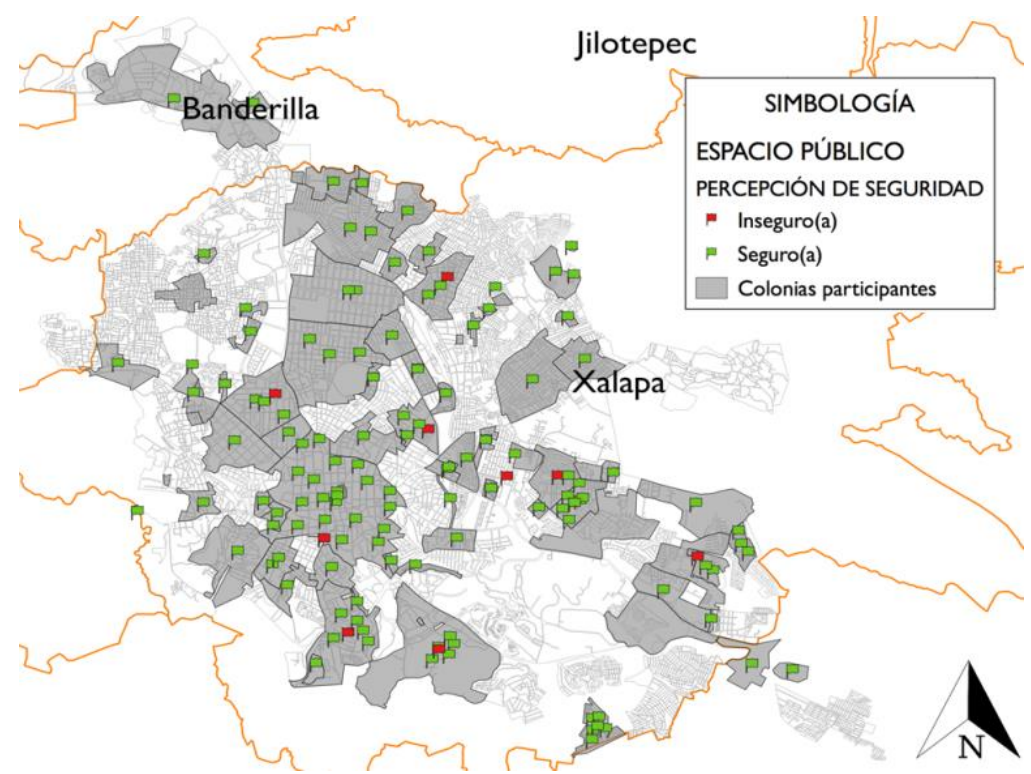

Figura 14. Percepción de seguridad. Encuesta virtual Entorno Residencial y Habitabilidad durante el confinamiento social por COVID-19.

Elaboración: Karla Lozano (2020).

En donde también se hace evidente la amena convivencia vecinal que existe entre las personas que habitan una misma colonia o barrio. Sin embargo, los entrevistados si mencionaron algunos problemas propios del desarrollo del confinamiento. Es de interés observar, de alguna forma una mayor cohesión social entre los vecinos de la periferia a diferencia de la convivencia vecinal que se advierte en el centro, en donde según un buen número de los encuestados, no cuentan con el apoyo de sus vecinos en caso de tener algún problema o solicitar ayuda, lo que finalmente podría aproximarnos a afirmar que no se conocen, ni presentan una cohesión social significativa (Figura 15). Diversas causas podrían ser motivo de este resultado, lo que si podemos apuntar es que los centros de las grandes ciudades se han convertido en espacios de consumo, servicios y gobierno y cada vez existen menos pobladores, y también ha existido migración del centro a la periferia, lo que podría ser un factor determinante en lo relacionado al entorno social.

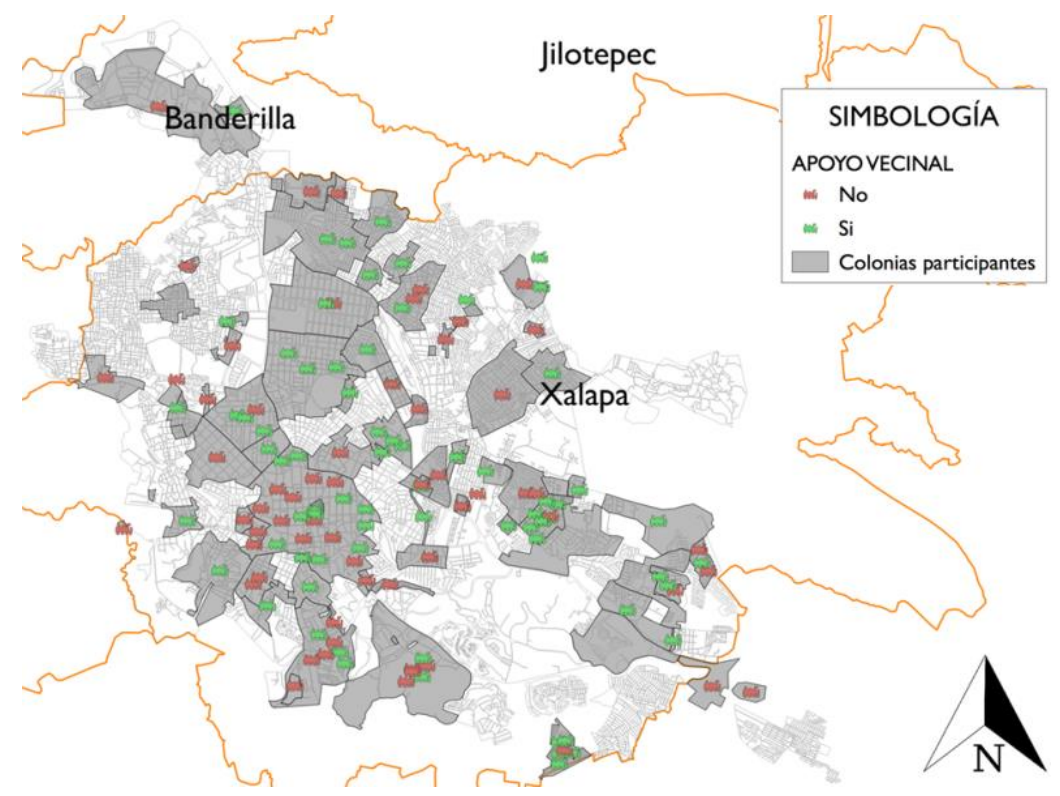

Figura 15. Apoyo vecinal Encuesta virtual Entorno Residencial y Habitabilidad durante el confinamiento social por COVID-19. Elaboración: Karla Lozano (2020). 


\section{Reflexiones y discusión}

Uno de los aspectos que confirman lo que hemos encontrado en otras investigaciones y a simple vista se nota en nuestras ciudades, es la falta de espacios verdes. En este estudio una tercera parte de los entrevistados mencionó contar con algún espacio verde cerca de sus viviendas. Sin embargo, el verde urbano brilla por su ausencia en la mayoría de los casos y lo que no sorprende es que otra tercera parte contestó no contar con algún espacio público para la recreación cerca o dentro de sus barrios. Este es un asunto pendiente en nuestras ciudades. Existen muchas colonias que no cuentan con un área para el esparcimiento y mucho menos un área en donde se puedan sus habitantes poner en contacto con la naturaleza, desestresarse y relajarse. Algo tan importante, en estos tiempos, en donde la ansiedad por el encierro se han convertido en otra situación a poner cuidado.

Los espacios públicos recreativos, como las áreas verdes dentro de los barrios y colonias juegan un rol súper importante en una situación de confinamiento y restricción de movilidad, pues estos pueden satisfacer la necesidad de respiro, naturaleza, paseo y juego en el entorno barrial. Sin embargo, muchos sectores de nuestras ciudades no cuentan con estos y si existen muchas veces están abandonados, sin mantenimiento y con poca o nula infraestructura.

En este sentido la calle también juega un rol importante dentro de los barrios como espacio público. Más allá de ser un espacio de circulación, considerarlo como un espacio recreativo dentro del entorno barrial es de suma importancia. Una mayoría comentó no poder usar su calle como espacio recreativo por alto número de vehículos que circulan por estas. Este es otro asunto para tener en cuenta en las estrategias para el mejoramiento barrial, que podrían estar acompañadas con el replanteamiento de la movilidad vehicular al interior de los barrios. Frecuentemente, encontramos una movilidad desordenada y sin jerarquización en las ciudades, esto en detrimento de los barrios y sus habitantes.

La vivienda es aspecto de gran importancia, y en este estudio nos interesa saber que tanto satisface las necesidades de sus habitantes durante el confinamiento. Al parecer la vivienda cuenta con los espacios necesarios para satisfacer las actividades domésticas y de esparcimiento, sin embargo, también nos damos cuenta, que estas no están configuradas para trabajar por largos periodos, pues muchas no cuentan con un área específica para esta actividad. Posiblemente, para el estudio, los estudiantes cuentan en sus recamaras con algún escritorio o mesa para estudiar, sin embargo este no es un lugar ideal para la concentración académica. En muchas otras viviendas, la gente trabaja o estudia en el área de comedor. Este sitio, tampoco es el idóneo, pues como sabemos las actividades se entremezclan y es difícil alcanzar niveles de concentración suficiente para realizar actividades laborales o de estudio.

Por otro lado, la distribución de equipamientos dentro de la ciudad y la localización de estos de manera ordenada, uniforme y de acuerdo a las necesidades de la población, es otro tema a atender, existen barrios desprovistos de equipamientos necesarios para satisfacer las diversas necesidades de la vida urbana. El repensar las ciudades de acuerdo a la distribución equitativa de los servicios y satisfactores a nivel barrial, se ha convertido en una tarea importante para muchos gestores de las ciudades en el mundo (el planteamiento de la ciudad de los 15 minutos, en el caso de Paris) para el caso mexicano deberá ser un asunto a considerarse.

\section{Conclusiones}

La pandemia remarca las deficiencias urbanas que muchos barrios y colonias de la ciudad padecen y pone sobre la mesa de discusión a los grupos y sectores sociales que por su localización en el territorio, son más vulnerables a padecer condiciones de vida con mayores deficiencias y menos oportunidades para satisfacer necesidades cotidianas de trabajo, estudio, así como recreación y socialización.

Al mismo tiempo la investigación nos hace reflexionar acerca de a difícil relación entre lo público y lo privado en nuestras ciudades en donde el flujo entre estos dos ámbitos se vuelve complejo ya que en lugar de ser elementos complementarios, se transforman en espacios totalmente opuestos y la limitación remarcada por la deficiencia y falta de igualdad en su provisión a lo largo y ancho de la ciudad, esto en total detrimento de la calidad de vida urbana que se ofrece a los habitantes.

Debido a lo anterior algunas de las propuestas de la investigación se centran en replantear las estrategias de mejoramiento urbano sobre todo en las zonas periféricas para configurar barrios y colonias más equilibrados 
así mismo plantear acciones para la vivienda y el espacio público que coadyuven con una mayor calidad de vida para la población.

Sabemos que la situación de pandemia se prologa por tiempo indefinido, y en el futuro posiblemente se vivirán otro tipo y más amenazas, la incertidumbre de volver a vivir la ciudad como en el pasado es un tema latente y se desconoce si será posible. Las ciudades, sus barrios y el entorno habitacional deberán ser abordados por la ciencia con visiones amplias, complejas que implican abordajes multi y transdisciplinares, para saber cómo adaptarnos a lo que nos imponen la cada vez más cambiante e incierta realidad.

\section{Reierencias}

Acuto, M. (2020). COVID-19: Lessons for an Urban(izing) World. https://www.ncbi.nlm.nih.gov/pmc/articles/PMC7159854/

Arief, A. (2020). The Magic of Empty Streets Social distancing gives us a rare chance to fix cities. The New York Times. April 8, 2020. https://www.nytimes.com/2020/04/08/opinion/coronavirus-tips-new-york-san-francisco.html

Borja, J., \& Muxi, Z. (2003). El Espacio Público: Ciudady Ciudadanía. Barcelona: Electa.

Carr, S., Francis, M. et al. (1992). Public Space. CambridgeL: Cambridge University Press.

Century 21 España (2020, 28 de octubre) "Estudio del Sector Inmobiliario y COVID en España". Comunicae. https://www.comunicae.es/nota/al-65-de-los-espanoles-les-gustaria-cambiar-de-1219104/

Espinoza, D. (2020). Vivienda y segregación social, la otras desigualdades que el Covid-19 hizo visibles. http://palabrapublica.uchile.cl/2020/04/30/vivienda-segregacion-social-covid19/

Fernández Nieto, B. (2020). Violencia Doméstica en México durante el confinamiento por la pandemia COVID-19. Data pop Alliance. Disponible en: https://datapopalliance.org/violencia-domestica-en-mexico-durante-elconfinamiento-por-la-pandemia-covid-19/

González, D. (2020). Vulnerabilidad de la vivienda, segunda causa principal en la propagación del Covid-19: CEMEX-TEC. Inmobiliare, edición Enero-Diciembre 2020. Fecha de acceso 22 de enero de 2021. Disponible en https://inmobiliare.com/vulnerabilidad-de-la-vivienda-segunda-causa-principal-en-la-propagacion-del-covid-19cemex-tec/

Hernández, F. (2020a). Cómo afecta la pandemia de Covid-19 a las ciudades. Centro Urbano. https://centrourbano.com/2020/04/23/como-afecta-covid-19-ciudades/

Hernández, F. (2020b). Expertos comparten aprendizajes post Covid-19 en las ciudades. Centro Urbano. https://centrourbano.com/2020/06/26/expertos-aprendizajes-post-covid-ciudades/

Hernández, F. (2020c) Pandemia muestra desigualdad en distribución del espacio público: ONU-Hábitat. Centro Urbano. https://centrourbano.com/2020/07/07/pandemia-desigualdad-espacio-publico/

Jacobs, J. (1961). The Death and Life of Great American Cities. New York: Random House.

Martí D., \& Velazquez, A. U. (2020). Urbanismo en tiempo de coronavirus, reflexiones sobre la actualidad y futuro de las ciudades latinoamericanas. En M. E. Sánchez Martínez \& F. J. De la Torre Galindo (Coord.) Anuario de Estudios Urbanos. Universidad Autónoma Metropolitana. México.

Ziccardi, A. (Responsable) (2020). Condiciones de habitabilidad de las viviendas y del entorno urbano ante el aislamiento social impuesto por el Covid-19 (informe preliminar). En línea, fecha de acceso 13 de julio 2020. Disponible en: https://www.iis.unam.mx/wp-content/uploads/2020/05/CONDICIONES-DE-HABITABILIDAD.pdf

Zicardi A., \& González, A.(coord.) (2015). Habitabilidad y política habitacional en México. México: UNAM. Fecha de acceso: 22 de enero de 2021 Disponible en: http://biblioteca.clacso.edu.ar/gsdl/collect/mx/mx063/index/assoc/D12852.dir/pdf_1447.pdf.

Zhong, Y., \& Teirlinck, B. (2020). Density and its Effect on COVID-19 Spread. Disponible en: https://edc.nyc/densityand-its-effect-on-covid-19-spread. Fecha de acceso 8 de feb. de 2021. 